\title{
Морфология поверхности и оптические свойства стеклообразных пленок селена после лазерной модификации
}

\author{
(C) Е.В. Александрович, А.Н. Александрович, С.Г. Быстров, Г.М. Михеев \\ Удмуртский федеральный исследовательский центр Уральского отделения Российской академии наук, \\ 426067 Ижевск, Россия \\ E-mail: evalex@udman.ru
}

Поступила в Редакцию 13 января 2021 г.

В окончательной редакции 21 января 2021 г.

Принята к публикации 21 января 2021 г.

\begin{abstract}
Представлены результаты исследований воздействия маломощного излучения $\mathrm{He}-\mathrm{Ne}$-лазера на длине волны 632.8 нм на морфологию поверхности стеклообразных (аморфных) пленок Se толщиной $\sim 1$ мкм, синтезированных вакуумно-термическим напылением. Показано, что в зависимости от интенсивности и времени воздействия излучения лазерная модификация пленок сопровождается различным изменением их шероховатости и появлением на поверхности исследуемых пленок структур, отличающихся размерами и фазовым составом. Формирование на поверхности лазерно-модифицированных пленок цепей субмикронных хребтов приводит к увеличению их коэффициента отражения, показателя преломления и уменьшению оптической толщины.
\end{abstract}

Ключевые слова: стеклообразный селен, пленки, поверхность, лазерная модификация, наноструктуры, атомно-силовая микроскопия.

DOI: 10.21883/FTP.2021.05.50835.9604

\section{1. Введение}

Известно, что аморфные (стеклообразные) пленки селена $(a-\mathrm{Se})$ востребованы в оптоэлектронике, фотовольтаике, голографии и других областях [1]. Однако они весьма нестабильны из-за очень низкой температуры размягчения $T_{g}\left(\sim 40^{\circ} \mathrm{C}\right)$ [2] и высокой концентрации поверхностных дефектов [3], способствующих их кристаллизации при нагревании [4] или при освещении [5]. Существуют различные способы проведения релаксации аморфной структуры пленок Se в более устойчивое состояние без их массовой кристаллизации. Одним из таких способов является метод создания на поверхности пленок Se рельефных решеток за счет проявления в пленках фотопластического эффекта [6,7]. Релаксации аморфной структуры также можно достичь, получив в пленках дополнительное разупорядочение с помощью изотермического отжига при температурах, близких к температуре $T_{g}[4,8,9]$, и лазерного воздействия [10-13].

Недавно нами было показано, что модификация пленок $a$-Se сфокусированным маломощным излучением $\mathrm{He}-\mathrm{Ne}$-лазера приводит к зарождению в них нанокристаллитов тригонального $\mathrm{Se}(t-\mathrm{Se})$ и моноклинного alpha-Se или beta-Se, хаотично распределенных в аморфной матрице $[14,15]$. Их появление сопровождается релаксацией пленок в стабильное структурное состояние, сохраняющееся при комнатной температуре в течение длительного времени. Кроме того, исследование спектров комбинационного рассеяния света (КРС) позволило выяснить, что в зависимости от плотности мощности используемого лазерного излучения и его времени воздействия в аморфной матрице пленок $a$-Se можно получить те или иные структуры с различными кристаллическими решетками, в том числе и с метастабильными. При этом структурные и фазовые изменения, происходящие в пленках $a$-Se, модифицированных в различных режимах $[14,15]$, а также их оптические свойства [16] существенно различаются. Возможное влияние морфологии поверхности лазерно-модифицированных пленок на данные изменения при этом не исследовано, что является целью настоящей работы.

\section{2. Методология исследований}

\section{1. Экспериментальные образцы}

Технология получения пленок стеклообразного $\mathrm{Se}$ и данные по исследованию их оптических и структурных свойств до и после лазерной модификации описаны в наших недавних работах $[9,14-16]$. В этих работах вакуумно-термическим испарением гранул элементарного Se особой степени чистоты $\left(0.9999\right.$, вакуум $10^{-3}$ Па) из платинового тигля были синтезированы пленки толщиной $\sim 1$ мкм на оптически прозрачных подложках. Полученные пленки являлись стеклообразными, рентгеноаморфными и имели характерный темно-красный цвет. В экспериментах толщину полученных пленок $h$ определяли с помощью интерференционного микроскопа МИИ-4 с точностью до 2-3\%. Из полученных образцов были отобраны образцы толщиной $h=1100 \pm 30$ нм.

\section{2. Лазерная модификация образцов}

Пленки, расположенные в плоскости, перпендикулярной падающему лучу, облучались $\mathrm{He}-\mathrm{Ne}$-лазером 

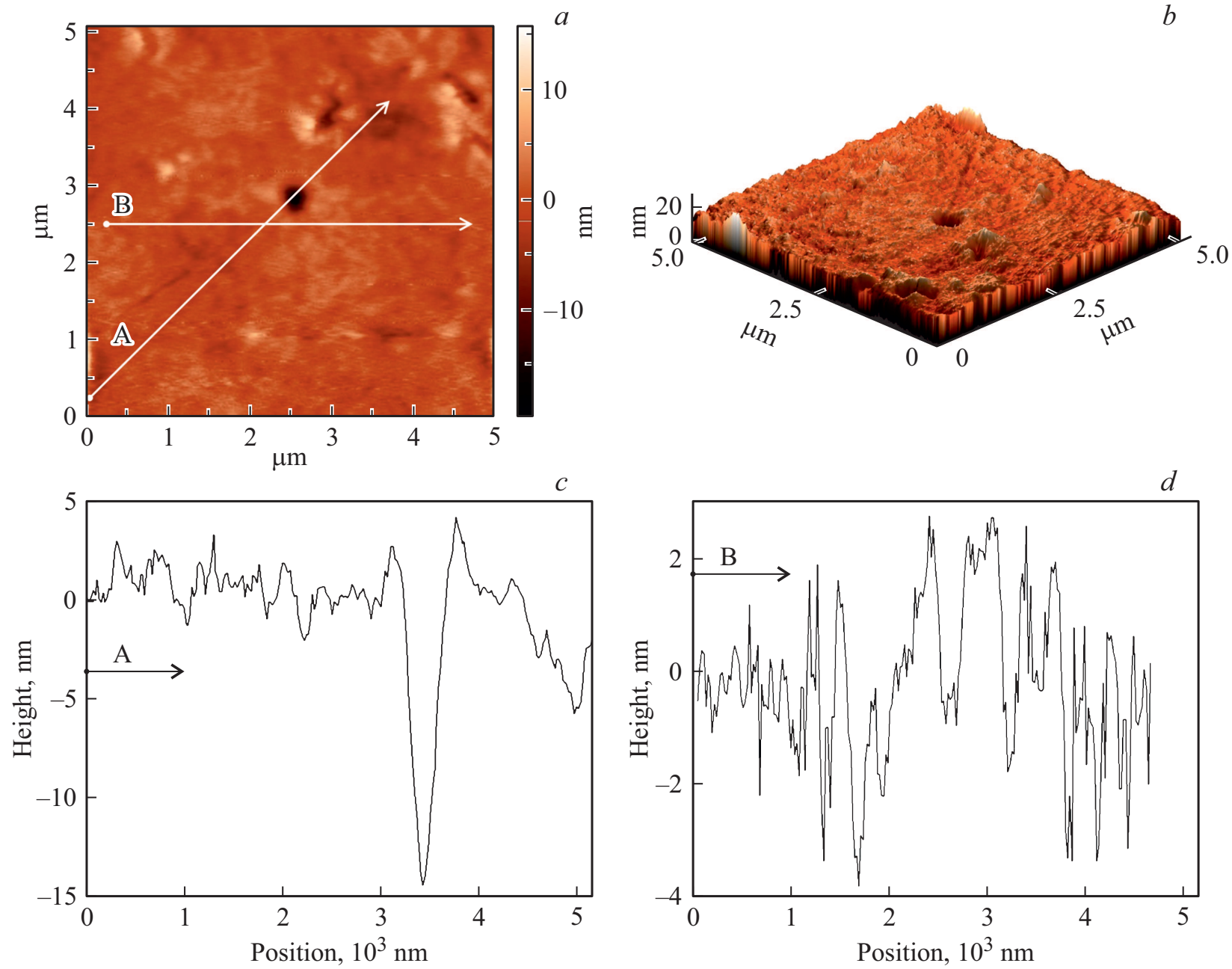

Рис. 1. Двумерное $(a)$ и трехмерное $(b)$ АСМ-изображения поверхности размерами $5 \times 5$ мкм свеженапыленной стеклообразной пленки $a$-Se и ее профили рельефа по координате вдоль линий $\mathrm{A}(c)$ и $\mathrm{B}(d)$ по направлению указанных стрелок на изображении $a$.

на длине волны 632.8 нм с различными плотностями мощности $P_{S}$ и временем экспозиции $\Delta t$. Лазерный луч фокусировался на поверхности пленок с помощью объектива $100 \times$. При этом размер лазерного пятна составлял 4.1 мкм.

\section{3. Экспериментальные методы исследований}

Методами спектрофотометрии, КРС, рентгеновской дифракции и просвечивающей электронной микроскопии были установлены различия фазовых трансформаций и оптических свойств модифицированных образцов, облученных в разных режимах. Наиболее значительные различия наблюдали при облучении с $P_{S}=80 \mathrm{BT} / \mathrm{cm}^{2}$ в течение времени $\Delta t=1 \mathrm{c}$ (группа образцов 1) и с $P_{S}=5.3 \mathrm{\kappa Вт} / \mathrm{cm}^{2}$ в течение времени $\Delta t=60 \mathrm{c}$ (группа образцов 2). Через шесть месяцев после лазерной модификации в условиях хранения пленок при комнатной температуре степень кристалличности образцов из групп 1 и 2 составляла $\sim 2-3$ и 30\% соответственно. При этом цвет пленок из группы образцов 1 оставался прежним - темно-красным, а у образцов из группы 2 становился серого цвета, характерного для кристаллического $t$-Se.

В настоящей работе представлены результаты исследований морфологии поверхности тонкопленочных образцов $a$-Se 1 и 2, являющихся типичными представителями вышеупомянутых групп. Морфология поверхности образцов исследовалась методом атомно-силовой микроскопии (ACM) на микроскопе SOLVER P47 PRO при комнатной температуре, в контактном режиме до облучения (контрольные образцы) и спустя шесть месяцев после лазерной модификации и стабилизации их фазового состояния и структурных и оптических свойств. Измерения облученных пленок проводились на модифицированных участках. Средняя арифметическая шероховатость поверхности $\left(R_{a}\right)$ и статистический параметр $R_{z}$ (максимальный перепад высот по 10 точкам поверхности) рассчитывались по изображениям 12 участков с базовыми размерами $2.5 \times 2.5$ мкм на фрагментах размерами $5 \times 5$ мкм для каждого образца с помощью программы Image Analysis 3.5.0. 

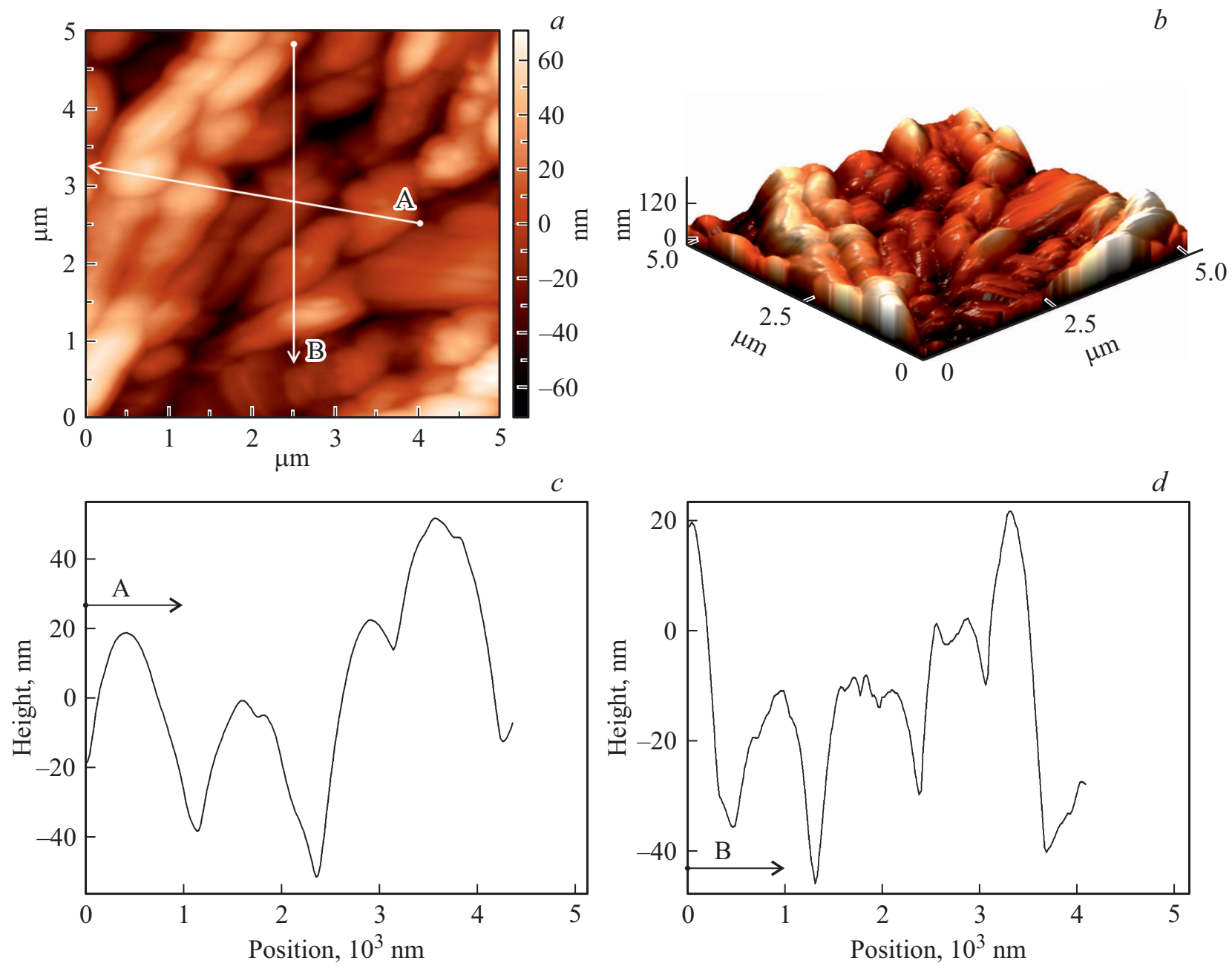

Рис. 2. Двумерное $(a)$ и трехмерное $(b)$ АСМ-изображения модифицированного фрагмента поверхности размерами $5 \times 5$ мкм образца 1 , облученного Не-Nе-лазером при $P_{S}=80 \mathrm{~B} / \mathrm{cm}^{2}$ и времени экспозиции $\Delta t=1$ с через шесть месяцев хранения после его модификации, а также профили рельефа по координате вдоль линий А $(c)$ и В $(d)$ по направлению указанных стрелок на изображении $a$.

При обсуждении результатов настоящей работы привлекались результаты исследований образцов 1 и 2 , полученные методом рентгенофазового анализа (РФА), спектры КРС [15], их оптические спектры, записанные в режиме отражения $R(\lambda)$ на спектрофотометре СФ-56 в волновом диапазоне $380-1100$ нм, а также их оптические характеристики, определенные нами в работе [16].

\section{3. Экспериментальные результаты}

\section{1. Атомно-силовая микроскопия пленок $\mathrm{Se}$}

На рис. 1 представлены двумерное и трехмерное

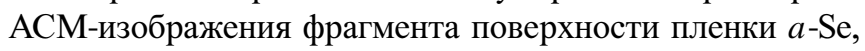
синтезированной на кварцевой подложке сразу после напыления (контрольный образец), и ее профили рельефа.

Из рис. 1 видно, что на поверхности свеженапыленной пленки имеются одиночные поры глубиной, достигающей 5-20 нм. Однако ее поверхность в целом является относительно гладкой: средние значения параметров $R_{a}$ и $R_{z}$ с учетом среднеквадратических отклонений $(\mathrm{CКO})$ составляют $1.5 \pm 0.3$ и $15 \pm 3$ нм соответственно. Измерения показали, что для кварцевой подложки параметры $R_{a}$ и $R_{z}$ имеют значения $0.39 \pm 0.04$ и $4.6 \pm 0.5$ нм соответственно.

На рис. 2 и 3 представлены АСМ-изображения и профили рельефа образцов 1 и 2 через шесть месяцев хранения после их лазерной модификации.

Обнаружено, что через шесть месяцев хранения после модификации средние значения параметров $R_{a}$ и $R_{z}$ с учетом СКО для образца 1 составили $18 \pm 2$ и $103 \pm 10$ нм, а для образца $2-12 \pm 2$ и $65 \pm 11$ нм соответственно. По сравнению со свеженапыленной пленкой $R_{a}$ и $R_{z}$ модифицированных образцов увеличились, но у образца 2 их значения оказались в $1.5-2$ раза меньше, чем у образца 1.

Из рис. 2 следует, что рельеф поверхности образца 1 через шесть месяцев после лазерной модификации со- 

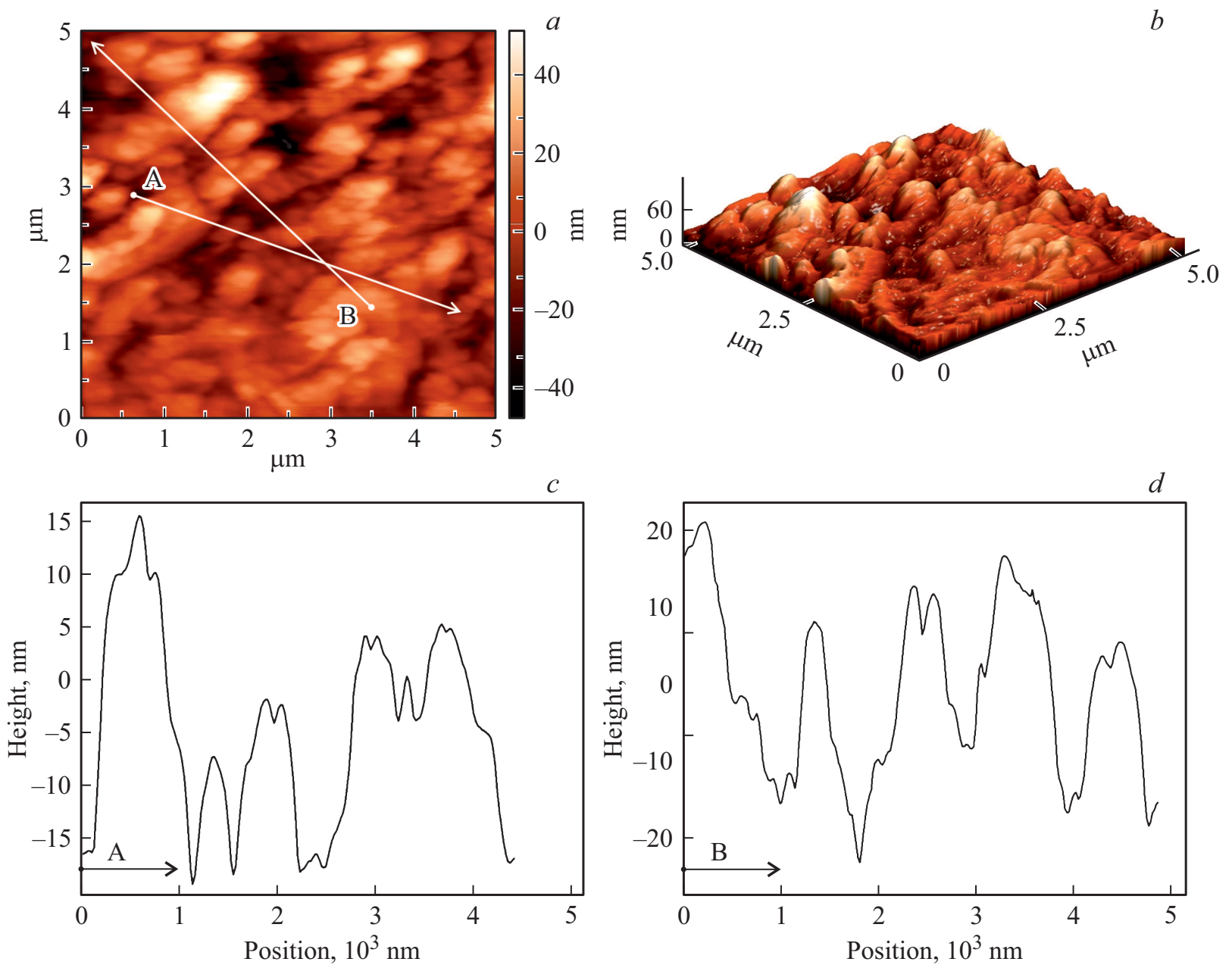

Рис. 3. Двумерное $(a)$ и трехмерное $(b)$ АСМ-изображения модифицированного фрагмента поверхности размерами $5 \times 5$ мкм образца 2 , облученного Не-Nе-лазером при $P_{S}=5.3 \mathrm{kB} / \mathrm{cm}^{2}$ и времени экспозиции $\Delta t=60$ с через шесть месяцев хранения после модификации, а также профили рельефа по координате вдоль линий А $(c)$ и В $(d)$ по направлению указанных стрелок на изображении $a$.

стоит из цепей хребтов, разделенных нанометровыми ущельями глубиной, достигающей 40-50нм. Хребты имеют ширину $\sim 0.5$ мкм и вершины высотой до 60 нм.

На АСМ-изображениях образца 2 (рис. 3) через шесть месяцев после его лазерной модификации с $P_{S}=5.3$ кВт/см ${ }^{2}$ хорошо видны субмикронные конгломераты, состоящие из мелких нанометровых бугорков высотой, достигающей 40 нм. Также можно заметить субмикронные впадины глубиной до 20 нм.

\section{2. Изменения оптических свойств лазерно-модифицированных пленок Se}

На рис. 4 представлены спектры коэффициентов отражения $R(\lambda)$, а на рис. 5 - дисперсионные зависимости оптической плотности $D(\lambda)$ и показателя преломления $n(\lambda)$ свеженапыленных и лазерно-модифицированных образцов 1 и 2, построенные на основе данных нашей работы [16].
После модификации с $P_{S}=80 \mathrm{BT} / \mathrm{cm}^{2}$ и хранении при комнатной температуре у образца 1 увеличиваются коэффициент отражения $R$ (рис. 4, $a$ ), показатель преломления $n$ и оптическая плотность $D$ (рис. $5, a$ ), а также в соответствии с данными работы [16] происходит уменьшение оптической щели $E_{g}$ и оптической толщины $\langle d\rangle$ с $1180 \pm 50$ до $1000 \pm 20$ нм.

После модификации с $P_{S}=5.3 \kappa \mathrm{BT} / \mathrm{cm}^{2}$ и хранении при комнатной температуре у образца 2 его $R$ (рис. $4, b)$ и $n$ (см. вставку на рис. $5, b$ ) уменьшаются. В соответствии с данными работы [16] $E_{g}$ данного образца также уменьшается, а $D$ увеличивается. Оптическая толщина $\langle d\rangle$ при этом увеличивается с $1070 \pm 50$ до $1270 \pm 40$ нм.

Таким образом, морфология поверхности, как и оптические свойства, идентичных исследуемых образцов $a$-Se (рис. 1) после лазерного облучения с различными $P_{S}$ и временем экспозиции $\Delta t$ после их хранения в течение шести месяцев при комнатной температуре существенно отличаются друг от друга (рис. 2, 3). 

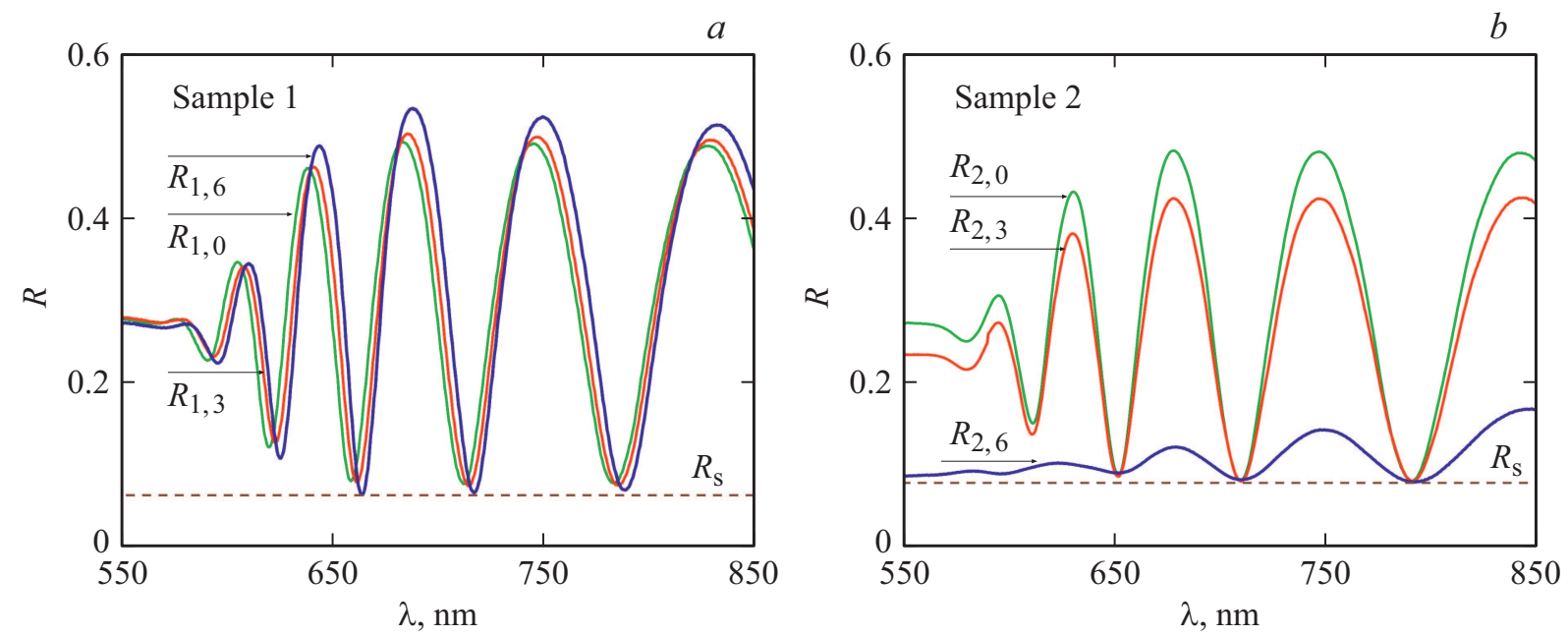

Рис. 4. Спектры отражения $R(\lambda)$ образцов $1(a)$ и $2(b)$ пленок Se. Кривые $R_{1,0}, R_{1,3}, R_{1,6}$ для образца 1 и кривые $R_{2,0}, R_{2,3}, R_{2,6}$ для образца 2 получены сразу после напыления и в процессе их хранения при комнатной температуре через три и шесть месяцев соответственно. $R_{s}(\lambda)$ - спектр отражения прозрачной кварцевой подложки.

\section{4. Обсуждение полученных результатов}

Ранее в [15] нами было установлено, что под воздействием сфокусированного лазерного излучения на длине волны 632.8 нм в пленках $\mathrm{Se}$ происходят фазовые превращения с появлением в аморфной матрице нанокристаллитов моноклинного и тригонального Se. Исходя из экспериментальных данных РФА и КРС [15] можно утверждать, что в исследуемых образцах $a$-Se c $E_{g}=2.05$ эВ под воздействием сфокусированного излучения с энергией кванта 1.96 эВ происходит локальный разогрев их поверхности. По-видимому, это происходит из-за существования в хвостах локализованных энергетических состояний стеклообразного $a$-Se многочисленных дефектов $[3,13]$. Их взаимодействие друг с другом при облучении приводит к фотоиндуцированному зарождению центров кристаллизации и их росту $[15,17]$. Очевидно, что количество центров кристаллизации в пленках, облученных с разной плотностью мощности, является различным, и их рост при облучении и в процессе дальнейшей релаксации при хранении сопровождается формированием той или иной морфологии поверхности пленок.

При лазерном воздействии с малой плотностью мощности $\left(P_{S}=80 \mathrm{BT} / \mathrm{cm}^{2}\right)$ в пленках $\mathrm{Se}$ не происходит разрывов химических связей и их переключений. Однако плотности мощности излучения $P_{S} \sim 80 \mathrm{BT} / \mathrm{cm}^{2}$ и времени экспозиции $\Delta t=1$ с достаточно, чтобы в облучаемых областях запустились процессы взаимодействия многочисленных дефектов друг с другом [18], в результате которых пленка становится более плотной, и ее геометрическая толщина $h(h=\langle d\rangle / n)$ уменьшается на $10-15 \%$, что следует из выше предоставленных данных. Кроме того, наличие в исходных стеклообразных пленках $\mathrm{Se}$ большой концентрации дефектных коротких цепочек $\mathrm{Se}-\mathrm{Se}$, состоящих из восьми атомов [15,19], является причиной того, что наиболее упорядоченные островки, появившиеся после модификации и находящиеся внутри аморфных частиц, кристаллизуются с образованием нанопроволок моноклинного beta-Se 8 с $n$, большим, чем у $a$-Se [16]. Взаимодействие дефектов и образование кристаллических нанопроволок происходит неравномерно по поверхности, что приводит к появлению хребтов с узкими нанометровыми ущельями между ними (рис. 2) и возрастанию шероховатости пленки с $R_{a}=1.5 \pm 0.3$ до $18 \pm 2$ нм и $R_{z}$ с $15 \pm 3$ до $103 \pm 10$ нм. В результате показатель преломления $n$ пленки и ее оптическая плотность $D$ увеличиваются (рис. 5, $a$, кривые $n_{1,6}$ и $D_{1,6}$ ), а наличие аморфной оболочки вокруг нанокристаллических структур препятствует массовой кристаллизации пленки (кристалличность составляет всего $\sim 2 \%)$. Из-за существования относительно глубоких ущелий $(\sim 50$ нм) шероховатость в данном образце по сравнению со свеженапыленной пленкой и образцом 2 является более высокой. Однако формирование протяженных хребтов субмикронной ширины (см. рис. 3) способствует сглаживанию огибающей профилей поверхности и вызывает увеличение отражательной способности $R$ образца 1 в максимумах на зависимостях $R(\lambda)$, представленных на рис. 4, $a$.

После лазерной модификации образца 2 с большей плотностью мощности $P_{S}=5.3 \mathrm{\kappa BT} / \mathrm{cm}^{2}$ спустя шесть месяцев его хранения формируется морфология поверхности, отличающаяся от морфологии образца 1. Появляются протяженные участки с меньшими значениями параметров $R_{a}$ и $R_{z}$, чем в образце 1 . Отличаются и профили поверхности (рис. 3, $c, d$ ). На фоне относительно гладкой поверхности и субмикронных конгломератов хорошо заметны многочисленные нанометровые бугорки и впадины глубиной до 20 нм (рис. 3). Хотя шероховатость по сравнению с образцом 1 является меньше в 1.5-2 ра- 

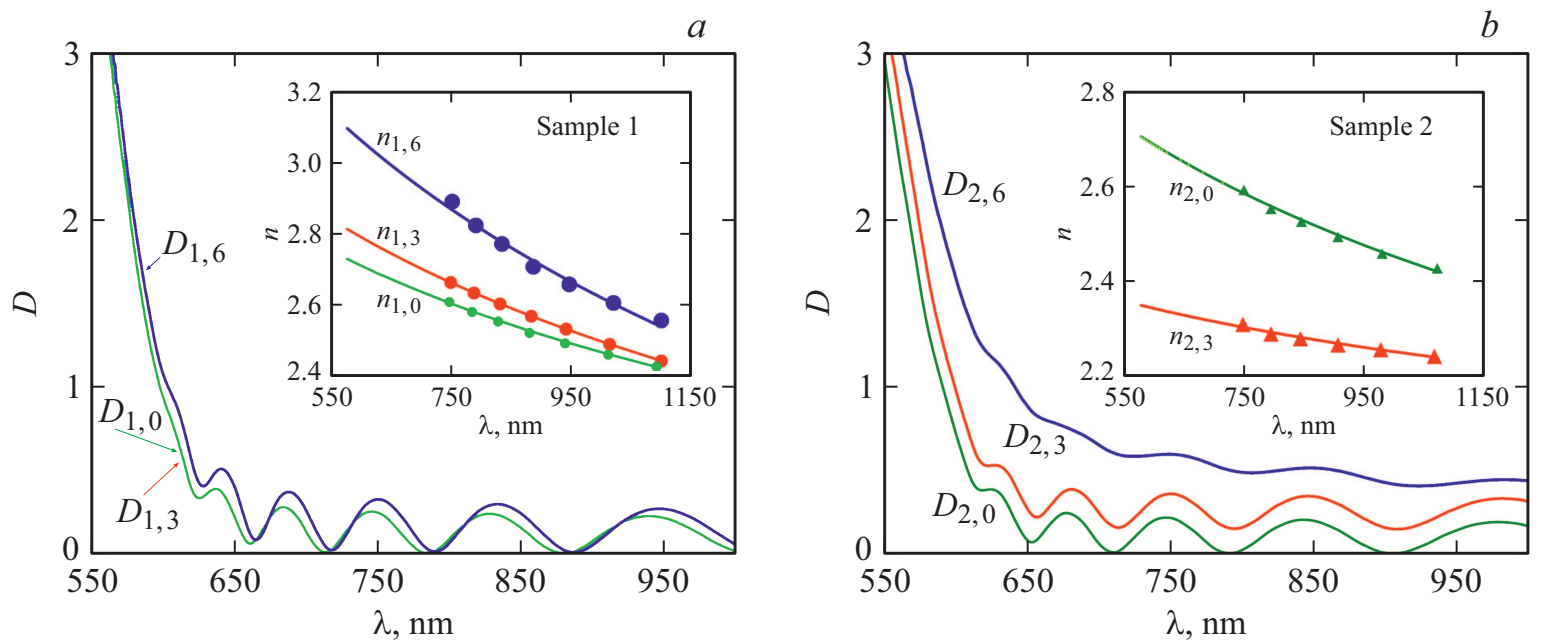

Рис. 5. Оптические плотности $D(\lambda)$ образцов $1(a)$ и $2(b)$ пленок Se. Кривые $D_{1,0}, D_{1,3}, D_{1,6}$ для образца 1 и кривые $D_{2,0}, D_{2,3}, D_{2,6}$ для образца 2 получены сразу после напыления и в процессе их хранения при комнатной температуре через три и шесть месяцев соответственно. На вставках приведены зависимости показателей преломления от длины волны $n(\lambda)$ образцов 1 (a) и $2(b)$. Кривые $n_{1,0}, n_{1,3}$ и $n_{1,6}$ для образца 1 и кривые $n_{2,0}$ и $n_{2,3}$ для образца 2 получены сразу после напыления и в процессе их хранения при комнатной температуре через три и шесть месяцев соответственно.

за, его оптическая $\langle d\rangle$ и геометрическая $h$ толщины уже спустя три месяца увеличиваются на $15-20 \%$. Также наблюдается более значительное, чем в образце 1 , увеличение его $D$ (рис. $5, b$ ) и уменьшение $E_{g}$ [16]. Исходя из экспериментальных данных РФА и КРС [15] можно предположить, что облучение образца 2 с большей плотностью мощности $P_{S}=5.3 \mathrm{\kappa}$ т $/ \mathrm{cm}^{2}$ и бо́льшим временем экспозиции 60 с, в сравнении с образцом 1 , приводит к более длительному и интенсивному взаимодействию в нем дефектов друг с другом и формированию кристаллических зародышей моноклинного и тригонального $\mathrm{Se}$ уже при облучении. Поверхность пленки, т. е. своеобразная ее морфология, в этом случае может формироваться вследствие роста кристаллов из появившихся в момент облучения центров кристаллизации, происходящего по механизму Странского-Крастанова [20]. Это объяснение подтверждается увеличением геометрической и оптической толщин образца 2 на фоне незначительного увеличения параметров шероховатости $R_{a}$ и $R_{z}$. При этом из-за недостаточности времени облучения формирование полностью закристаллизованной области и полное полиморфное превращение alpha-Se в $t$-Se не происходят. Следует отметить, что с момента лазерной модификации образца 2 до его стабилизации спустя шесть месяцев его кристалличность увеличивается с 23 до 30\%, хотя средние размеры кристаллитов, образовавшихся непосредственно после лазерного воздействия, в процессе его хранения не изменяются и составляют $~ 30$ нм [15]. Из-за форсированного разогрева облученных участков в местах соприкосновения аморфной и кристаллической областей появляются упругие напряжения $[17,19]$. Релаксация упругих напряжений вызывает увеличение кристалличности и распространение кристаллизации на прилегающие к местам облучения соседние аморфные области. При этом происходит окончательное формирование морфологии поверхности данного образца. Увеличение объемной доли кристаллитов, с одной стороны, а с другой - сохранение неупорядоченности в пленке вызывают появление рэлеевского рассеяния [21] при облучении светом в спектральном диапазоне 500-1100 нм. В результате в образце 2 показатель преломления $n(\lambda)$ (см. вставку на рис. 5, $b$, кривая $n_{2,3}$ ) и коэффициент отражения $R(\lambda)$ (рис. $4, b$, кривые $R_{2,3}$ и $R_{2,6}$ ) уменьшаются.

\section{5. Заключение}

Таким образом, из результатов данной работы следует, что маломощным лазерным излучением с энергией возбуждения, близкой к энергии оптической щели стеклообразных пленок $\mathrm{Se}$, полученных вакуумно-термическим испарением, можно влиять на морфологию их поверхности. Показано, что даже невысокая плотность мощности излучения $P_{S} \sim 80 \mathrm{~B} / \mathrm{cm}^{2}$ и незначительное время облучения $\Delta t=1$ с вызывают существенные изменения в морфологии поверхности лазерно-модифицированных пленок с появлением в них цепей хребтов субмикронной ширины с нанопроволоками моноклинной фазы beta-Se. Установлено, что локальное изменение структуры поверхности пленки $a$-Se вызывает уменьшение ее геометрической и оптической толщины и увеличение показателя преломления $n$ и коэффициента отражения $R$, а также сопровождается переходом пленки в более устойчивое энергетическое состояние при комнатной температуре. Выявлено, что в режиме лазерной модификации с $P_{S}=5.3 \kappa \mathrm{BT} / \mathrm{cm}^{2}$ и временем экспозиции $\Delta t=60 \mathrm{c}$ на поверхности пленки можно сформировать аморфнокристаллические конгломераты с нанокристалитами три- 
гонального и моноклинного alpha-Se. Показано, что при этом происходит увеличение ее геометрической и оптической толщины, увеличение кристалличности и уменьшение оптических параметров $n$ и $R$. Маломощное лазерное излучение может быть использовано при модификации поверхности пленок при создании тонких аморфно-кристаллических слоев Se с пространственномодулированными структурами, имеющих устойчивые оптические свойства.

\section{Финансирование работы}

Работа выполнена в рамках государственного задания Министерства образования и науки Российской Федерации (государственный регистрационный номер АААА-А19-119021890083-0). Данное исследование выполнено с использованием оборудования центра совместного использования „Центра физических и физико-химических методов анализа и изучения свойств и поверхностных характеристик наноструктур, материалов и изделий“ УдмФИЦ УрО РАН.

\section{Конфликт интересов}

Авторы заявляют об отсутствии конфликта интересов.

\section{Список литературы}

[1] A.M. Patil, V.S. Kumbhar, N.R. Chodankar, A.C. Lokhande, C.D. Lokhande. J. Colloid and Interface Sci., 469, 257 (2016).

[2] C.-Y. Chang, Y.-J. Lin, Y.-W. Huang, J.-Y. Liao, J.-S Lin, F.-M. Pan. J. Mater. Sci.: Mater. Electron., 29, 15203 (2018).

[3] T. Scopigno, W. Steurer, S.N. Yannopoulos, A. Chrissanthopoulos, M. Krisch, G. Ruocco, T. Wagner. Nature Commun., 2, 195 (2011).

[4] F. Mutar, A. Hemed. Adv. Phys. Theor. Appl., 31, 16 (2014).

[5] R.E. Tallman, B.A. Weinstein, A. Reznik, M. Kubota, K. Tanioka, J.A. Rowlands. J. Non-Cryst. Sol., 354, 4577 (2008).

[6] M.L. Trunov, P.M. Lytvyn, S.N. Yannopoulos, I.A. Szabo, S. Kökényesi. Appl. Phys. Lett., 99, 051906 (2011).

[7] M.L. Trunov, P.M. Lytvyn, P.M. Nagy, A. Csik, V.M. Rubish, S. Kökényesi. Phys. Status Solidi B, 251, 1354 (2014).

[8] A.H. Goldan, C. Li, S.J. Pennycook, J. Schneider, A. Blom., W. Zhao. J. Appl. Phys., 120, 135101 (2016).

[9] Е.В. Александрович, Е.В. Степанова, К.Г. Михеев. Хим. физика и мезоскопия, 17 (1), 86 (2015).

[10] G.P. Lindberg, T. O'Loughlin, N. Gross, A. Reznik, S. Abbaszadeh, K.S. Karim, G. Belev, D.M. Hunter, B.A. Weinstein. Can. J. Phys., 92, 728 (2014).

[11] V.K. Tikhomirov, P. Hertogen, G.J. Adriaenssens, C. Gloriux, R. Ottenburgs. J. Non-Cryst. Sol., 227-230, 732 (1998).

[12] K. Okano, I. Saito, T. Mine, Y. Suzuki, T. Yammada, N. Rupesinghe, G.A.J. Amaratunga, W.I. Milne, D.R.T. Zahn. J. Non-Cryst. Sol., 353, 308 (2007).

[13] R. Sharma, D. Kumar, V. Srinivasan, H. Jain, K.V. Adarsh. Opt. Express, 23, 14085 (2015).

[14] Е.В. Александрович, Е.В. Степанова, К.Г. Михеев, Г.М. Михеев. Письма ЖТФ, 44, 86 (2018).
[15] E.V. Aleksandrovich, K.G. Mikheev, G.M. Mikheev. Eur. Phys. J. Special Topics, 229, 197 (2020).

[16] E.V. Aleksandrovich, A.N. Aleksandrovich, G.M. Mikheev. J. Non-Cryst. Sol., 545, 120249 (2020).

[17] V.K. Tikhomirov, P. Hertogen, C. Glorieux, G.J. Adriaenssens. Phys. Status Solidi A, 162, R1 (1997).

[18] A.V. Kolobov, H. Oyanagi, Kaz. Tanaka, K. Tanaka. Phys. Rev. B, 55, 726 (1997).

[19] A. Roy, A.V. Kolobov, H. Oyanagi, Kaz. Tanaka. Phil. Mag. B, 78, 87 (1998).

[20] A. Baskaran, P. Smereka. J. Appl. Phys., 111, 044321 (2012).

[21] В.А. Викулов, А.М. Маслов, А.А. Дмитриев, В.В. Коробцов. Опт. и спектр., 103, 986 (2007).

Редактор Г.А. Оганесян

\section{Surface morphology and optical properties of glassy selenium films after laser modification}

\section{E.V. Aleksandrovich, A.N. Aleksandrovich, S.G. Bystrov, G.M. Mikheev}

Udmurt Federal research center of the Ural branch of the Russian Academy of Sciences, 426067 Izhevsk, Russia

Abstract The results of studies of the effect of low-power $\mathrm{He}-\mathrm{Ne}$ laser radiation at a wavelength of $632.8 \mathrm{~nm}$ on the surface morphology of glassy (amorphous) Se films with a thickness of $\sim 1 \mu \mathrm{m}$ synthesized by vacuum-thermal evaporation are presented. It is shown that depending on the intensity and time of radiation exposure, laser modification of films is accompanied by various changes in their roughness and the appearance of structures on the surface of the films under study that differ in size and phase composition. The formation of submicron ridge chains on the surfaces of laser-modified films leads to an increase in their reflection coefficient and refraction index and a decrease in their optical thickness. 